\title{
Research of the Shape of Pressure Arch in Layered Rock Mass Based on the Protodyakonov's Theory
}

\author{
WU Xin ${ }^{1, \text { a }}$, TU Zihan ${ }^{2, b}$ \\ ${ }^{1}$ College of Engineering, Sichuan Normal University, Chengdu, Sichuan 610101, China \\ ${ }^{2}$ College of Engineering, Sichuan Normal University, Chengdu, Sichuan 610101, China \\ amuchelwu@hotmail.com, ${ }^{\text {b } 304194631 @ q q . c o m}$
}

\begin{abstract}
Keywords: layered rock mass; Protodyakonov's theory; pressure-arch; support.
Abstract. layered rock mass is a common geological structure in the underground engineering construction, and the Protodyakonov's theory is widely used in the calculation of underground caving arch, however, the actual occurrence state of engineering surrounding rock is much more complex than homogeneous rock mass of the Protodyakonov's theory. Firstly, researching the influence of span and rock hardness coefficient of the arch line equation under the Protodyakonov's theory on the shape of pressure-arch respectively, then dividing the horizontally-layered strata into two strata which are upper-hard lower-soft ground and upper-soft lower-hard ground, researching the forms of the pressure-arches for two strata based on the Protodyakonov's theory. The purpose is to provide the scientific guidance for roadway support of the 11912 working face of the Xingtai mining area.
\end{abstract}

\section{Introduction}

The actual underground engineering is located in the complex geological body, The stratum distribution may be horizontal or inclined or even vertical, it's also possible that the surrounding rocks are distributed as a lens. To the tunnels which have a certain buried depth, all the unconformities, joints, cleavages, stratifications and other strata structural forms in the rock mass will cause certain influences on the pressure-arch effect of the surrounding rocks produced by tunnel constructions. The theory of the surrounding rock pressure, which appeared earlier and had been widely applied and improved by most scholars is Protodyakonov's theory, Terzaghi's theory, etc.

Currently, there were some scholars had used the Protodyakonov's theory to study the height, stress, stability of pressure-arch in wall rock. In addition, theoretical analyses and experimental researches had been done by some scholars regarding aspects such as the deformation and failure mechanism, the shear failure characteristics, mechanical characteristics, bending deformation[1-11]:Li Peng-fei, Wang Fan, Nie Xiong and others[1] carried out a study about the methods for calculating rock pressure of symmetrical multi-arch deep tunnels, a formula for calculating the rock pressure under deep buried conditions was derived according to the Protodyakonov's theory; Gu Shuan-cheng,Fan Qi,Wang Jian-wen and others[4] studied the methods for calculation roof caving arch height of roadway roof in layered rock mass, derived the calculation formulas for layered caving and full caving of horizontal and inclined stratified rock mass based on the Protodyakonov's theory respectively, and verified through practical engineering examples that calculation formula for layered caving was more applicable to practical conditions; According to the mechanical behavior and the deformation failure of layered rock mass, Zuo Shuang-ying, Shi Wen-bing, Liang Feng and others[6] established an anisotropic constitutive model for layered rock mass to reflect the transversely isotropic characteristics based on the FLAC3D.

In the following, influence factors for the shape of the Protodyakonov's pressure-arch were analyzed. For further research of the complex shape of the pressure-arch in layered rock mass, the horizontally-layered strata were divided into two strata which were upper-hard lower-soft ground and upper-soft lower-hard ground, then researching the shapes of pressure-arch of the two strata structural forms respectively. In order to provide the scientific guidance for the rock support. 


\section{Brief Description of Engineering}

Xingtai mining area is located in Xingtai City, Hebei Province, the whole mine area is about 90km long and $70 \mathrm{~km}$ wide, covering an area of around $630 \mathrm{~km} 2$. The east well of Gequan mine in Xingtai mining area is encountering the problem which the complex roof is difficult to support. The detection result of rock structure of the mining roadway roof in 11912 working face shows that: There are about $650 \mathrm{~m}$-long combined seam of No.8 and 9 coal seam in the tunnel starting from the open-off cut, and unexposed Daqing limestone above the No.8 coal seam is highly weathered, a thick overburden is covered on Daqing limestone). In this way, highly weathered Daqing limestone and weakly weathered Daqing limestone of the coal seam above the roadway have formed different strata with respect to widely divergent physicochemical properties. The range of loose zone obtained through the Protodyakonov's theory in such cases may have higher errors. Therefore, the shape of pressure-arch formed in heterogeneous stratified surrounding rocks should be considered.

\section{The Calculating Formula and Influencing Factors of the Protodyakonov's Theory}

The Protodyakonov's Theory was proposed by a Russian scholar named Protodyakonov in 1907, which is also called Natural Balance Arch Theory. It holds that a parabolic natural balance arch is formed over the excavated underground opening in loose medium with a certain cohesive force, while the surrounding rock pressure acting on the retaining structure is the gravity of the loose rock mass inside the natural balance arch. A part of the rock above the natural balance arch bears the entire gravity from the overlaying strata. It is like a load-bearing ring which passes down the load to both sides. This is the pressure-arch effect of the wall rocks.

In order to obtain the pressure of the wall rocks from the top of the cave, we have to confirm the equation for the arch axis of the natural balance arch, and then determine the distance from the top of the cave to the arch axis, so that we can calculate the weight of rock inside the natural balance arch. If we have any point $\mathrm{M}(\mathrm{x}, \mathrm{y})$ from the equation, based on the Protodyakonov's Theory:

$$
y=\frac{x^{2}}{a_{1} f}
$$

Where, f--consistent coefficient of the rock strength;

$\mathrm{a}_{1}$--the largest span of the natural balance arch;

a--the span of the arch when the sidewall is stable;

$\mathrm{x}, \mathrm{y}-$-the coordinate of $\mathrm{M}$.

From the arch axis equation we can see that the shape of Protodyakonov's pressure arch only has connection with consistent coefficient f and span a and has nothing to do with other factors. According to the data fitting, in the case of a determinate span, the smaller the Protodyakonov's coefficient is, the higher the formed pressure-arch is and most importantly the range of the loose zones is increasing rapidly, resulting in higher and higher requirements on support. When the Protodyakonov's coefficient is determinate, the larger the span is, resulting in a higher height of the pressure-arch .

Fig. 1 simulated the heights of the pressure-arches and the areas of loose zones respectively. When the consistent coefficients are 1,3,5,7,9 and 11 under the condition that the span is fixed. Supposing that the span is $8 \mathrm{~m}$, what can be seen from Fig. 1 is when $\mathrm{f}=1$, the height of the pressure-arch is the highest, and the loose scope is also largest. When $\mathrm{f}=3,5,7,9$ and 11 , the heights of the pressure-arches decrease in turn, the ranges of the loose zones are gradually decreasing. When $\mathrm{f}=11$, the height of the pressure-arch is the lowest, the loose scope is also smallest.

The following picture shows the shapes of the pressure-arch formed under different span. When $f=3$, it can be seen from the figure that when the spans increase in turn, the heights of the pressure-arches increase accordingly. When $\mathrm{a}=9$, the height of the pressure-arch is lowest. When $\mathrm{a}=3,5$ and 7 , the heights of the pressure arches are between the maximum and minimum. 

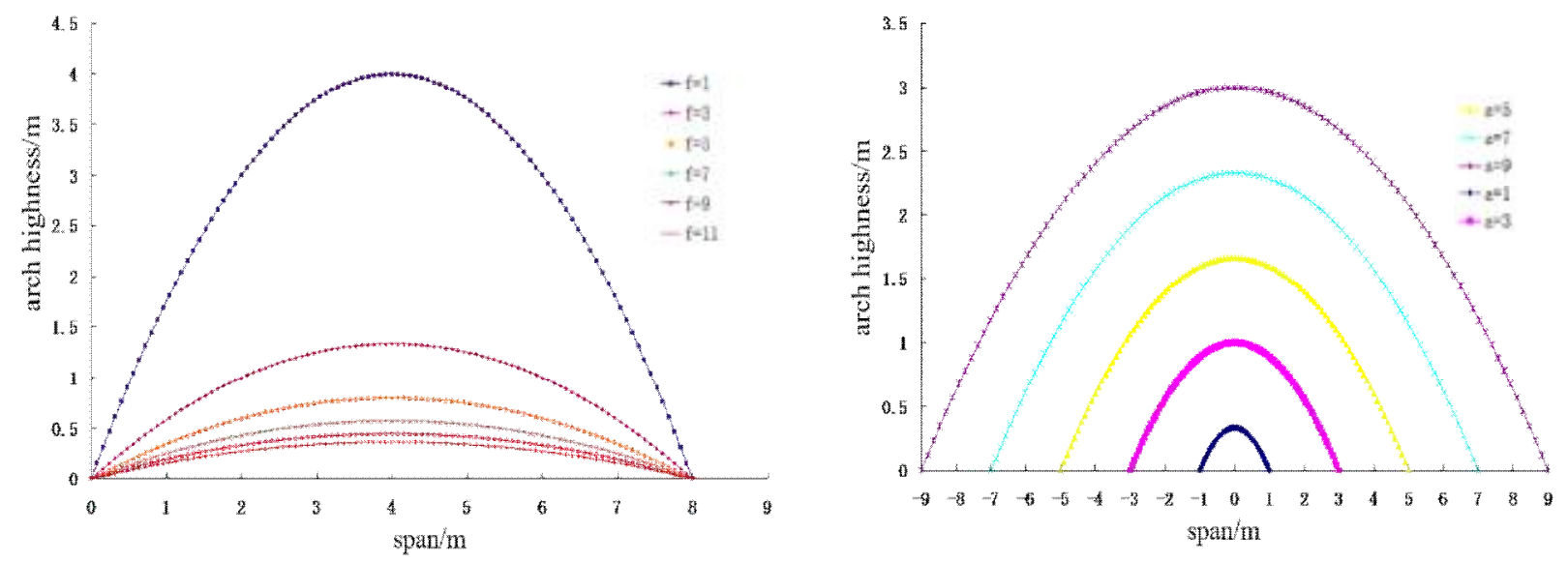

Fig.1 the shapes of pressure-arch

\section{The Corollary of Pressure-Arch in Layered Strata}

From the above analysis, it can be concluded that the shape of the pressure-arch is fixed when the formation and the span of tunnel are both determinate. The application of the pressure-arch theory is extended to horizontally-layered strata can obtain many forms of pressure-arch similar to practical conditions based on this idea. There are many types of combination of horizontally-layered strata. In order facilitate the analysis, the horizontally-layered strata have been divided into two types which are upper-hard lower-soft ground and upper-soft lower-hard ground. In addition, also assuming that the both sides are stable.

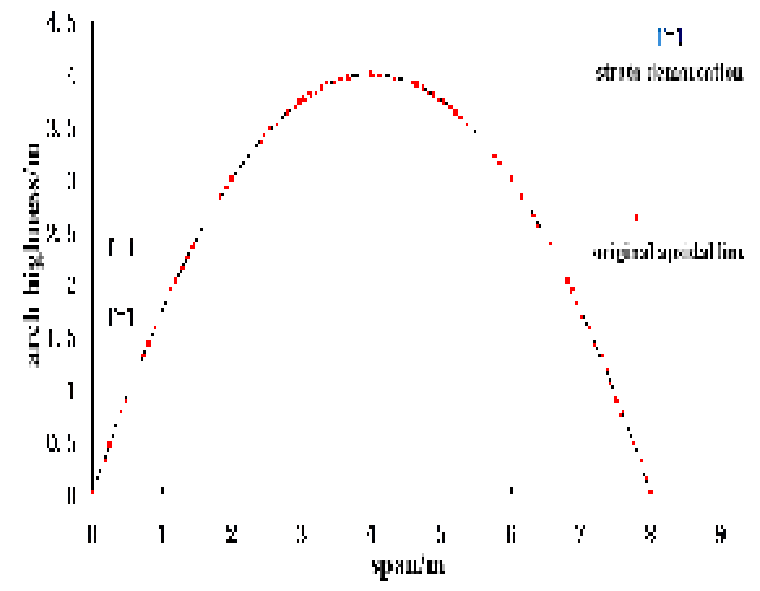

(a)

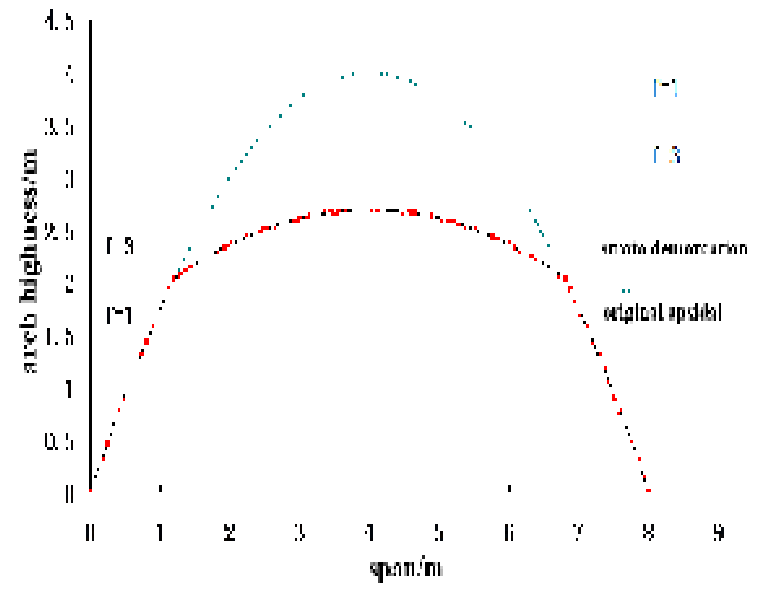

(c)

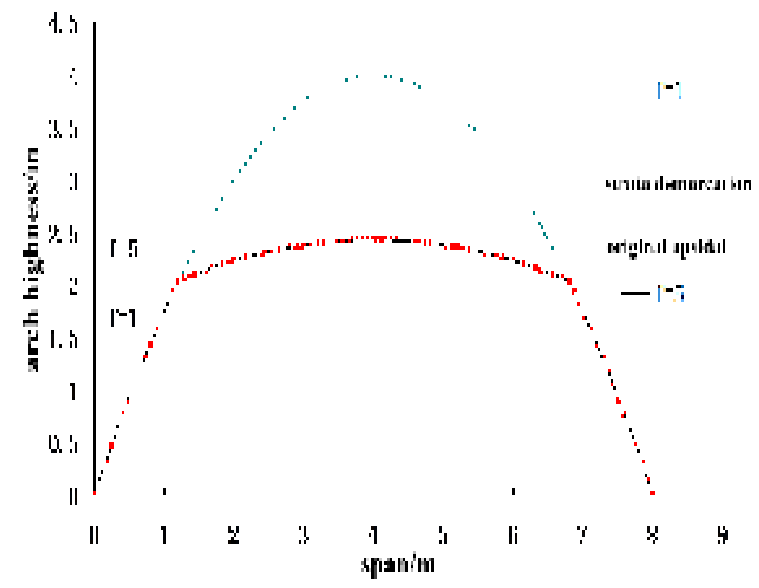

(b)

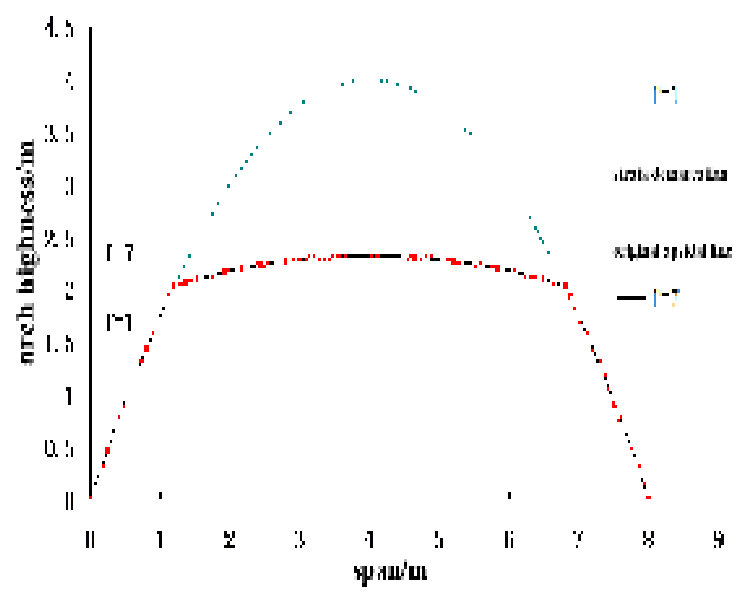

(d)

Fig.2 Different $f$ coefficients between upside and underside (I) 
First of all, the upper-hard lower-soft ground is analyzed (Fig.2). The surrounding rock is composed of two layers is been assumed, the separatrix is 2 meters away from the top of the roadway. 2 meters above the roadway roof is hard rock, and 2 meters below the roadway roof is soft rock. The hardness of the overlying hard rock is $\mathrm{f}=1,3,5$ and 7 respectively, while the hardness of the lower soft rock is $\mathrm{f}=1$. Obviously, as for the case of $\mathrm{f}=1$, the height of the pressure-arch of the rock strata exceeds $2 \mathrm{~m}$, and the exceeding part will go into the hard rock to continue the formation of pressure-arch.. When the fof the upper and lower layer are both 1, the pressure-arches are a unified parabola, which is the same as the single-layer rock mass case. When the hardness of the upper layer is $\mathrm{f}=3$, the arch height of the upper pressure-arch is reduced, the lower part remains the original shape. When the hardness of the upper layer is $\mathrm{f}=5,7$, the height of the upper layer pressure-arch continues to decrease, and the lower part remains changeless.

Secondly, the upper-soft and lower-hard ground is analyzed (Fig.3). Also assuming that the surrounding rock is composed of two layers. The separatrix is 0.4 meters away from the top of the roadway. 0.4 meters above the roadway roof is soft rock, the following is hard rock. The hardness of the overlying soft rock is $f=7,5,3,1$ respectively, while the hardness of the lower rock is $f=7$. Obviously, as for the case of $\mathrm{f}=7$, the height of the pressure-arch of the rock strata exceeds $0.4 \mathrm{~m}$, and the exceeding part will go into the soft rock to continue the formation of pressure-arch. It's shape is shown below. When the fof the upper and lower layer are both 7, the pressure-arches are a unified parabola, which is the same as the single-layer rock mass case. When the hardness of the upper layer is $f=5$, the arch height of the upper pressure-arch is reduced, the lower part remains the original shape. When the hardness of the upper layer is $f=3,1$, the height of the upper layer pressure-arch continues to decrease, and the lower part remains changeless.

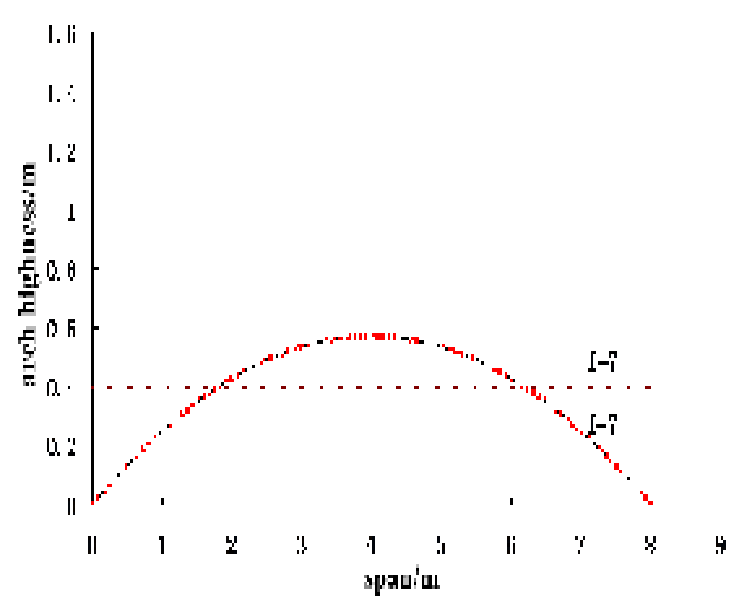

(a)

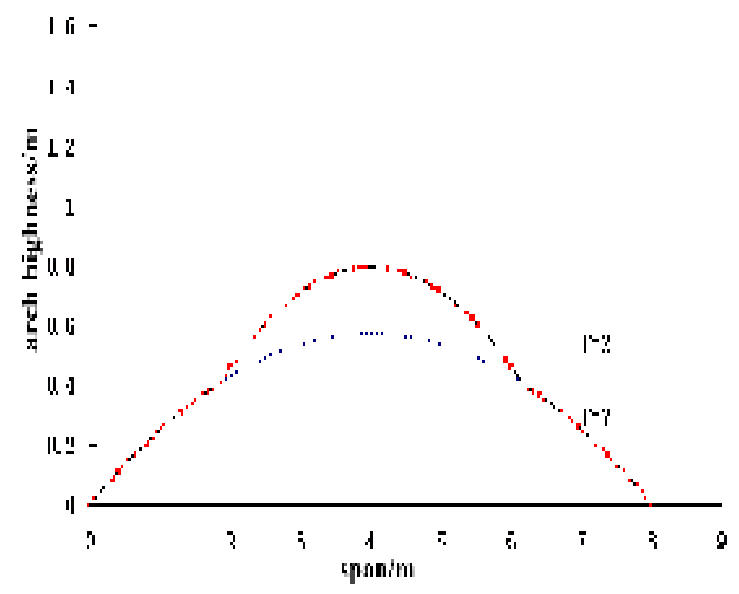

(c)

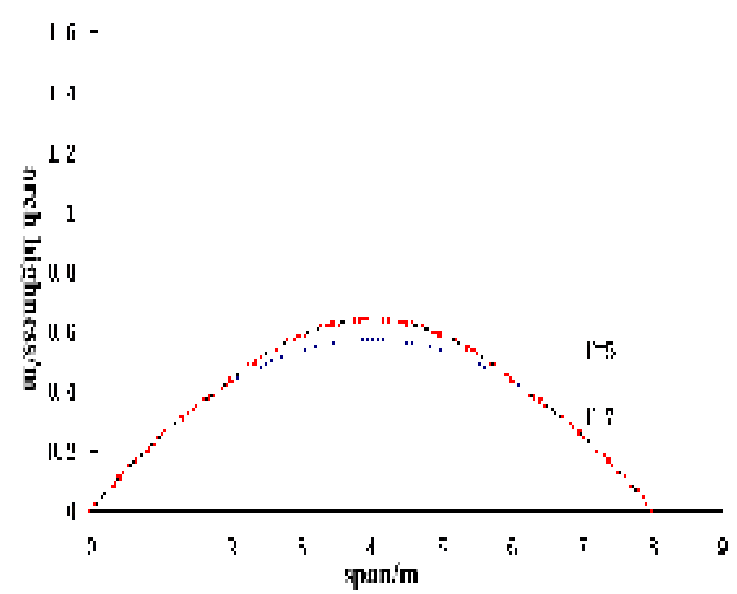

(b)

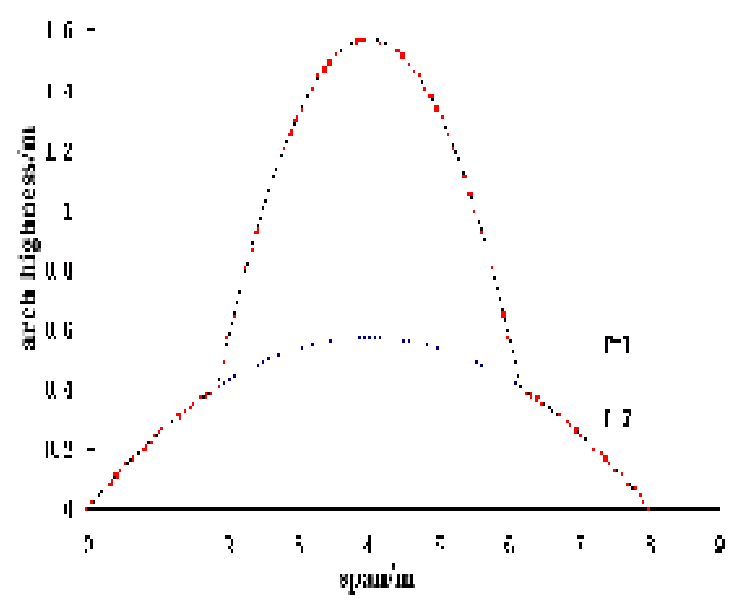

(d)

Fig.3 Different $f$ coefficients between upside and underside (II) 


\section{Conclusions}

The factors influencing the shape of the Protodyakonov's pressure-arch are analyzed. The result shows that if the span is fixed, the smaller the Protodyakonov's coefficient is, the higher the pressure-arch is and if the rock hardness coefficient is fixed, the larger the span is, the higher the height of the pressure-arch is.

The horizontal strata were divided and analyzed into two situations including upper-hard lower-soft ground and upper-soft lower-hard ground. The surrounding rock is composed of two layers was been assumed, the basic shape and collapse area of compound pressure-arch were obtained based on layered Protodyakonov's theory.

The above analysis can provide the scientific guidance for the roadway support of the 11912 working face. The roadway of 11912 working face is in thick coal seam., there is a coal seam about 3 meters above the roadway roof. While the overlying strata above the coal seam are highly weathered Daqing limestones and weakly weathered Daqing limestones and objectively forming two kinds of stratum structures which are upper-hard lower-soft ground and upper-soft lower-hard ground.

\section{Acknowledgements}

A Project Supported by Scientific Research Fund of Sichuan Provincial Safety Supervision Bureau (Grant No. scaqjgjc_stp_20150011) and Sichuan Normal university ordinary project (Grant No. 14YB01).

\section{References}

[1] LI Peng-fei, WANG Fan, NIE Xiong, et al.Methods for calculating rock pressure of symmetrical multi-arch deep tunnels[J].Chinese Journal of Geotechnical Engineering, 2016, 38 (9) : 1625-1629..

[2] HUANG Qing-xiang, ZHENG Chao.Theory of self-stable ring in roadway support[J].Rock and Soil Mechanics, 2016, 37 (5) : 1231-1236.

[3] ZHAO Jin-hai, YIN Li-ming, ZHANG Shi-chuan, et al.Strip tunneling method of rock roadway and stability simulation analysis of surrounding rock[J].MINING R \& D，2015，35（4）: 84-87.

[4] GU Shuan-cheng, FAN Qi, WANG Jian-wen, et al.Methods for caving arch height of roadway roof in layered rock mass[J].COAL ENGINEERING, 2012, （12）: 73-76.

[5] DAI Jun, QIAO Yan-peng, GUANG Xiang-can, et al.A method of measuring the height of caving arch of roadway in coal mine[J].MINING R \& D, 2009, 29 (6) : 26-27.

[6] ZUO Shuang-ying, SHI Wen-bing, LIANG Feng, et al.Numerical simulation and engineering application for failure modes and criterion of layered anisotropic rock mass[J].Chinese Journal of Geotechnical Engineering, 2015, 37 (S1) : 191-196.

[7] GU Shuan-cheng, WANG En-bo, SHI Xiang-dong.Spandrel failure mechanism analysis of arched roadway in layered rock mass[J].SAFETY IN COAL MINES，2014，45（11）: 172-179. 
[8] HUANG Shu-ling, DING Xiu-li, WU Ai-qing, et al.Study of multi-joint constitutive model of layered rockmass and experimental verification[J].Chinese Journal of Rock Mechanics and Engineering, 2012, 31(8) : 1627-1635.

[9] ZHOU Ke-feng, LI Yu-zhi, LIU Qun-yi.Numerical analysis of structure plane characteristic for strength of stratified rock mass[J].Journal of Central South University (Science and Technology) , 2012, 43 (4) : 1421-1428.

[10] LI Xiao-hong, XIA Bin-wei, LI Dan, et al.Deformation characteristic analysis of layered rockmass in deep buried tunnel[J].Rock and Soil Mechanics, 2010, 31 (4) : 1163-1167.

[11] HAN Chang-rui, ZHANG Bo, BAI Shi-wei, et al.Research on elastoplastic constitutive model of layered surrounding of a deep buried tunnel[J].Rock and Soil Mechanics, 2008, 29 (9) : 2404-2414.

[12] SHEN Ming-rong.Rock mechanics[M].Shanghai: Tongji University Press， 2004:163- 